\title{
HUBUNGAN ANTARA MOBILISASI DINI DENGAN PENYEMBUHAN LUKA PERINEUM RUPTUR TINGKAT I DAN II PADA IBU NIFAS DI PUSKESMAS TURIKALE MAROS
}

\author{
Uliarta Marbun \\ STIKES Nani Hasanuddin Makassar \\ Alamat Korespondensi: (uliartamarbun86@gmail.com/082195021525)
}

\begin{abstract}
ABSTRAK
Ibu yang melahirkan dengan ruptur perineum sampai saat ini perlu di perhatikan karena kurangnya pengetahuan ibu tentang perawatan luka perineum, kebersihan diri yang mengakibatkan infeksi. Karena itu mobilisasi sangat penting dalam mempercepat penyembuhan luka dan mengurangi resiko terjadinya infeksi masa nifas, menganjurkan ibu mobilisasi dini karena tidak hanya mempercepat penyembuhan luka perineum tetapi juga memulihkan kondisi tubuh ibu jika dilakukan dengan benar dan tepat, mobilisasi dini atau gerakan mungkin bisa mencegah aliran darah terhambat, hambatan aliran darah bisa menyebabkan terjadinya infeksi pada luka perineum. Tujuan penelitian ini Mengetahui hubungan antara mobilisasi dini pada ibu nifas dengan penyembuhan luka perineum. Jenis penelitian ini bersifat deskriptif kuantitatif dengan metode fieid reseach, Sampel pada penelitian ini adalah semua ibu post partum yang mengalami ruptur perineum sebanyak 34 responden. Pengambilan sampel dalam penelitian ini menggunakan teknik purposive sampling, data di kumpulkan melalui lembar observasi,Hasil penelitian menunjukan terdapat hubungan yang bermakna antara mobilisasi dini dan proses penyembuhan luka perineum dengan uji Chi-Square nilai $\rho=0,002$, nilai $\rho<\alpha$ 0.05. Dapat disimpulan bahwa ada hubungan antara mobilisasi dini terhadap penyembuhan luka pereneum pada ibu nifas di puskesmas turikale kabupaten maros. Sehingga di sarankan agar meneliti hubungan antara mobilisasi dini dengan penyembuhan luka perineum guna meningkatkan pengetahuan dan kemajuan dimasa yang akan datang.
\end{abstract}

Kata kunci : Luka Perineum, Mobilisasi Dini

\section{PENDAHULUAN}

Masa nifas dimulai sejak plasenta lahir dan berakhir ketika alat kandungan kembali seperti keadaan sebelum hamil. Masa nifas berlangsung kira-kira 6 minggu atau 42 hari, merupakan waktu yang diperlukan untuk pulihnya alat kandungan pada keadaan yang normal (Fitri I, 2018 : hal.1) Beberapa perubahan fisiologi yang terjadi selama masa nifas yaitu terjadi pengerutan uterus yang merupakan organ reproduksi interna yang berongga dan berotot, berbentuk seperti buah alpukat yang sedikit gepengdan berukuran sebesar telur ayam. panjang uterus $7-8 \mathrm{~cm}$, lebar sekitar $5-5,5 \mathrm{~cm}$, dan tebal sekitar $2,5 \mathrm{~cm}$ (Maritalia D, 2017 : hal.7) Setiap ibu nifas beresiko mengalami gangguan fungsi organ tubuh, tersumbatnya aliran darah dan gangguan fungsi otot rangka

Robekan perineum adalah: Robekan yang terjadi pada perimeum sewaktu persalinan dan terjadi pada hampir semua persalinan pertama dan tidak jarang juga pada persalinan berikutnya.Rupture perineum merupakan bagian dari pintu bawah panggul yang berada diantara vulva dan anus(Fatimah, 2019:67)
Berdasarkan hasil penelitian didapatkan ibu post partum dengan penyembuhan luka perineum baik ( $\leq 7$ hari) sebanyak $62,5 \%$. Lama penyembuhan luka perineum yang baik adalah 6-7 hari setelah persalinan (Mochtar, 2011). Luka dinyatakan sembuh apabila luka kering, tidak ada kemerahan, tidak ada pembengkakan, jaringan menyatu dan tidak nyeri ketika duduk dan berjalan. Penyembuhan luka perineum yang lama akan meningkatkan resiko terjadinya infeksi pada masa nifas (Rukiyah, 2011).

World Health Organization (WHO) tahun 2009 menyebutkan terjadi 2,7juta kasus rupture perineum pada ibu bersalin, angka ini diperkirakan akan mencapai 6,3 juta pada tahun 2050. Prevalensi ibu bersalin yang mengalami rupture perineum di Indonesia pada golongan umur 25-30 tahun yaitu $24 \%$ dan pada usia 32-39 tahun sebesar $62 \%$ (Afandi, 2014).

Berdasarkan hasil data dari tahun 20152019 di puskesmas Turikale Kabupaten Maros Provinsi Sulawesi Selatan mengalami peningkatan ibu nifas setiap tahun, tahun 2015 dengan jumlah 93 ibu nifas, tahun 2016 
sebanyak 111 ibu nifas, 2017 sebanyak 151 ibu nifas dan tahun 2018 sebanyak 212 ibu nifas.

\section{METODE DAN BAHAN}

Jenis penelitian ini bersifat deskriptif kuantitatif yang digunakan apabila dalam mendeskripsikan penelitian menggunakan angka dengan analisis univariat berupa persentase kemudian disajikan dalam bentuk tabel distribusi (ariani AP,2014:60). Dengan mengobservasi yang bertujuan untuk memperoleh hubungan antara mobilisasi dini pada ibu nifas dengan penyembuhan luka perineum

Metode penelitian yang digunakan adalah field reseach yang merupakan penelitian kuantitatif dimana penelitian mengamati dan berpartisipasi secara langsung.

\section{HASIL}

Penelitian ini di lakukan di puskesmas Turikale Kabupaten Maros yang di lakukan pada bulan mei sampai dengan bulan juli tahun 2019.jumlah sampel sebanyak 34 Orang responden yang di dapatkan dengan menggunakan teknik porposive sampling yang sesuai dengan kriteria yang di tetapkan

Hasil penelitian kemudian ditabulasi dan di analisa didasarkan univariat dan analisis bivariat yang di sajikan dalam bentuk tabel distribusi Karakteristik

1. Umur Responden

\begin{tabular}{|c|c|c|}
\hline Umur & $\mathrm{n}$ & $\%$ \\
\hline $17-20$ & 12 & 35,29 \\
\hline $21-25$ & 15 & 44,11 \\
\hline $26-30$ & 7 & 20,58 \\
\hline Total & 34 & 100 \\
\hline
\end{tabular}

Bedasarkan Tabel 1, maka diketahui bahwa tingkat umur yang paling banyak adalah 21-25 tahun dengan jumlah responden sebanyak 15 orang $(44,11 \%)$, sedangkan tingkat umur yang paling sedikit adalah 26-30 tahun dengan jumlah responden sebanyak 7 orang $(20,58 \%)$

2. Mobilisasi dini Responden

\begin{tabular}{|c|c|c|}
\hline Mobilisasi dini & $\mathrm{n}$ & $\%$ \\
\hline Selalu & 17 & 50,0 \\
\hline Jarang & 17 & 50,0 \\
\hline Total & 34 & 100,0 \\
\hline
\end{tabular}

Berdasarkan tabel 2, maka diketahui bahwa dari 34 responden yang selalu melakukan mobilisasi dini sebanyak 17 responden $(50,0 \%)$ yang jarang melakukan mobilisasi dini sebanyak 17 responden $(50,0 \%)$.
3. Penyembuhan Luka perineum responden

\begin{tabular}{|c|c|c|}
\hline $\begin{array}{c}\text { Penyembuhan } \\
\text { luka perineum }\end{array}$ & $\mathrm{n}$ & $\%$ \\
\hline Cepat & 21 & 61,8 \\
\hline Lambat & 13 & 38,2 \\
\hline Total & 34 & 100,0 \\
\hline
\end{tabular}

Berdasarkan tabel 3, maka diketahui bahwa dari 34 responden yang cepat penyembuhan luka perineum sebayak 21 Responden $(61,8 \%)$ yang lambat penyembuhan luka perineum sebanyak 13 responden $(38,2 \%)$.

4. Hubungan Mobilisasi Dini Dengan penyembuhan luka perineum Pada lbu Nifas di Wilayah Kerja Puskesmas Turikale Maros

\begin{tabular}{|c|c|c|c|c|}
\hline \multirow{3}{*}{$\begin{array}{l}\text { Mobilisasi } \\
\text { Dini }\end{array}$} & \multicolumn{4}{|c|}{$\begin{array}{l}\text { Penyembuhan luka } \\
\text { perineum }\end{array}$} \\
\hline & \multicolumn{2}{|c|}{ Cepat } & \multicolumn{2}{|c|}{ Lambat } \\
\hline & $\mathrm{n}$ & $\%$ & $\mathrm{n}$ & $\%$ \\
\hline Selalu & 15 & 10,5 & 2 & 6,5 \\
\hline Jarang & 6 & 10,5 & 11 & 6,5 \\
\hline Total & 21 & 21,0 & 13 & 13,0 \\
\hline
\end{tabular}

Berdasarkan tabel 4 maka diketahui bahwa dari 34 responden terdapat 15 responden $(10,5 \%)$ yang selalu melakukan mobilisasi dini dan cepat penyembuhan luka perineumnya, serta $2(6,5 \%)$ responden yang mobilisasi selalu dan lambat penyembuhan luka perineumnya. Serta 6 $(10,5 \%)$ jarang melakukan mobilisasi dini tetapi cepat penyembuhan luka perineum, serta $11(6,5 \%)$ responden yang jarang melakukan mobilisasi dini dan lambat penyembuhan luka perineumnya.

\section{PEMBAHASAN}

Berdasarkan hasil uji Chi-Square diperoleh nilai $\rho=0,002$ dengan demikian $\rho<\alpha$ 0.05 , sehingga Ho ditolak dan Ha diterima dengan interpretasi "ada hubungan mobilisasi dini dengan penyembuhan luka perineum pada ibu nifas di Wilayah Kerja Puskesmas Turikale Maros"

Hasil penelitian menunjukkan bahwa dari 34 responden terdapat 15 responden $(10,5 \%)$ yang selalu melakukan mobilisasi dini apabila di lakukan 2 sampai 4 kali dalam sehari misalnya pada saat bangun tidur pagi, siang dan malam dalam waktu 24-48 jam akan mempercepat penyembuhan luka perineumnya, serta 11 responden $(6,5 \%)$ yang jarang mobilisasi dini tidak melakukan 2 sampai 4 kali dalam waktu 24-48 jam akan memperlambat penyembuhan luka perineumnya.

Dari hari pertama sampai hari ketiga postpartum diketahui bahwa sebagian besar 
responden dalam kategori umur 21-25 tahun sebanyak15 (10.5\%) responden. Dari 17 responden terdapat $15(10,5 \%)$ mobilisasi selalu cepat penyembuhan lukanya karena diduga responden tidak merasakan kekhawatiran berlebihan untuk bergerak dini, responden tidak menolak jika diarahkan melakukan mobilisasi dari tempat tidur ke kamar kecil untuk buang air kecil dan mengikuti arahan menyusui bayinya dengan posisi miring kiri dan membalas menyusui bayinya dengan posisi miring kanan sehingga memperlancar sirkulasi peredaran darah mengurangi infeksi pada perineum, serta terdapat $2(6,5 \%)$ responden yang mobilisasi selalu dan lambat penyembuhan luka perineumnya karena responden tidak berinisiatif untuk menyusui bayinya sehingga tidak ada pergerakan dini serta ibu merasa takut dan menolak beranjak bangun dari tempat tidur kemudian berjalan buang air kecil sebab luka jahitan pada perineum yang masih baru, merasa takut jika jahitan pada perineum terbuka dan memilih buang air kecil di tempat tidur, sehingga posisi yang dilakukan responden hanya terlentang, miring kekiri, serta terdapat 6 responden $(10,5 \%)$ jarang melakukan mobilisasi dini tetapi cepat penyembuhan luka perineum karena responden sering mengkomsusi makanan yang berizi berupa sayur-sayuran hijau, ikan, kacang-kacangan, danging, buah-buahan, dan kebutuhan nutrisi cukup, serta personal hygiene yang teratur dilakukan setiap hari. responden jarang melakukan mobilisasi tetapi pengetahuan tentang gizi sangat mempengaruhi penyembuhan luka perineum. Faktor-faktor yang mempengaruhi penyembuhan luka perineum ibu postpartum sala satunya kebutuhan nutrisi dan cara perawatannya. Serta terdapat 11 (6,5\%) responden yang jarang melakukan mobilisasi dan lambat penyembuhan luka perineumnya karena diduga responden merasa takut untuk bergerak miring ke kiri dan ke kanan, takut jika luka jahitan terbuka pengetahuan dan pengalaman masih kurang karena merupakan persalinan pertama namun ibu tidak menolak menyusui bayinya dengan posisi berbaring sambil miring meskipun hanya miring satu arah yaitu ke kiri, ibu tidak menolak arahan yang di berikan untuk mobilisasi dari tempat tidur kekamar kecil untuk buang air kecil serta perawatan personal hygiene yang dilakukan setiap hari.

Robekan perineum adalah Robekan yang terjadi pada perimeum sewaktu persalinan dan terjadi pada hampir semua persalinan pertama dan tidak jarang juga pada persalinan berikutnya.
Perawatan perimeum merupakan pemenuhan kebutuhan untuk menyehatkan daerah antara paha yang dibatasi vulva dan anus pada ibu dalam masa kelahiran plasenta sampai dengan kembalinya organ genatik seperti pada waktu sebelum hamil. Kebanyakan robekan perimeum terjadi sewaktu melahirkan dan penanganannya merupakan masalah kebidanan.

Rupture perineum merupakan bagian dari pintu bawah panggul yang berada diantara vulva dan anus

Menurut Smeltzer (2002), fase-fase penyembuhan luka perineum pada ibu nifas ada fase inflamasi ( 1 sampai 4 hari), fase proliferative (5 sampai 20 hari), fase maturasi (21 sampai sebulan atau bahkan tahunan). Sedangkan menurut Hamilton (2007) kecepatan penyembuhan tergantung pada letak dan kedalaman insisi.Luka dikatakan sembuh jika terjadi kontinuitas lapisan kulit dan kekuatan jaringan kulit mampu atau tidak mengganggu untuk melakukan aktifitas normal.

Berdasarkan hasil penelitian yang didapatkan ibu post partum dengan penyembuhan luka perineum baik sebanyak $(10,5 \%)$. Lama penyembuhan luka perineum yang baik adalah 6-7 hari setelah persalinan menurut (Mochtar, 2011). Luka dinyatakan sembuh apabila luka kering, tidak ada kemerahan, tidak ada pembengkakan, jaringan menyatuh dan tidak nyeri ketika untuk duduk dan berjalan. Penyembuhan luka perineum yang lama akan meningkatkan resiko terjadinya infeksi pada masa nifas (Rukiyah, 2011).

Menurut penelitian fitri (2013) menyebutkan bahwa luka perineum bisa sembuh $<7$ hari (cepat) dan $\geq$ hari (lambat).Hasil penelitian ini sejalan dengan penelitian afandi (2014), yang menyebutkan bahwa $76 \%$ responden mengalami pecepatan penyembuhan luka perineum baik.

Hasil Penelitian ini sejalan dengan penelitian yang dilakukan Dian Marlina (2018) yang berjudul "Hubungan Antara Mobilisasi Dini Pada ibu Nifas Dengan Penyembuhan Luka Perineum Di Puskesmas Bara-Baraya makassar". Dari hasil uji statistic menggunakan uji Chi-Squaredengan tarif signifikan 5\% $(0,05)$ didapatkan $p$ value sebesar0,000. Jika $p$ value $=0,000$ maka $p$ lebih kecil dari alpha $(p>0,05)$ jadi Ho ditolak dan Ha diterima. Kesimpulan dari uji tersebut adalah menunjukkan bahwa ada hubungan yang sangat erat yaitu hubungan mobilisasi dini dengan penyembuhan luka perineum.

Menurut Eka Puspita Sari, dkk (2014) menyatakan bahwa mobilisasi yang dilakukan dengan benar dan tepat secara bertahap yakni dimulai dengan gerakan miring ke kanan dan 
kekiri, dan pada hari kedua ibu telah dapat duduk serta pada hari ketiga ibu telah dapat menggerakkan kaki yakni dengan berjalanjalan dan bisa mncegah terjadinya trombosis venadalam atau (DVT) Deep Vein Trombosis yang bisa menyebabkan terjadinya infeksi.

Untuk kebutuhan eliminasi dari hari pertama sampai hari ke tiga postpartum diketahui bahwa dari 34 responden semua dapat berkemih tanpa kateter dihari pertama sampai hari ketiga diduga karena pemenuhan kebutuhan cairan terpenuhi namun untuk defikasi dari 34 responden terdapat 2 responden yang kebutuhan eliminasi berupa defikasinya terpenuhi diduga karena selain kebutuhan caran yang terpenuhi ibu juga mengonsumsi makanan yang berserat tinggi seperti buah pisang yang dipadukan dengan kacang yang berguna untuk membantu produksi ASI(air susu ibu). Dan untuk pengeluaran lochea dari hari pertama sampai hari ke tiga postpartum diketahui bahwa dari 34 responden didapatkan pengeluaran lochea rubra yang masih berwarna merahsegar cair dan stolsel berupa gumpalan darah dari luka plasenta dan serabut dari desiduas dan chorian

Hasil penelitian ini juga di dukung oleh penelitian yang dilakukan oleh Anur Rohmin, dkk (2017) yang berjudul "factor resiko yang mempengaruhi lama penyembuhan luka perineum pada ibu post partum " hasil dari uji statistik menggunakan uji Chi-Square diperoleh nilai $p=0,000$, maka dapat di simpulkan bahwa ada yang signifikan aantara mobilisasi dini dengan penyembuhan luka perineum pada ibu post partum Penelitian ini juga di dukung oleh penelitian yang dilakukan oleh Willy Asrtiana (2017) yang berjudul "Mobilisasi dini ditinjau dari penyembuhan luka perineum di RS TK IV DR. Noesmir Baturaja

\section{KESIMPULAN}

Diketahui bahwa dari 34 responden terdapat 15 responden $(10,5 \%)$ yang selalu melakukan mobilisasi dini dan cepat penyembuhan luka perineumnya, serta 2 $(6,5 \%)$ responden yang selalumelakukan mobilisasi dini dan lambat penyembuhan luka perineumnya, serta terdapat 6 responden $(10,6 \%)$ jarang melakukan mobilisasi dini tetapi cepat penyembuhan luka perineum, serta 11 responden $(6,5 \%)$ yang jarang mobilisasi dini dan lambat penyembuhan luka perineumnya,

Berdasarkan hasil dan tujuan penelitian tentang hubungan mobilisasi dini dengan penyembuhan luka perineum pada ibu nifas di Wilayah Kerja Puskesmas Turikale Maros, dapat disimpulkan bahwa Ada hubungan antara mobilisasi dini pada ibu nifas dengan penyembuhan luka perineum di wilayah kerja puskesmas Turikale Kabupaten Maros.

\section{SARAN}

Berdasarkan hasil dan kesimpulan dari penelitian, maka peneliti memberikan beberapa saran antara lain sebagai berikut:

1. Kepada ibu nifas : ibu nifas yang melakukan persalinan di Puskesmas Turikale agar melakukan pergerakan dini atau mobilisasi dini secara teratur setiap hari untuk penyembuhan luka perineum

2. Kepada tenaga kesehatan : agar lebih giat lagi memberikan informasi tentang mobilisasi dini dan memastikan ibu nifas melakukan mobilisasi dengan benar dan teratur.

3. Kepada peneliti selanjutnya : agar meneliti hubungan mobilisasi dini dengan penyembuhan luka perineum dengan metode yang berbeda guna peningkatan dan kemajuan ilmu pengetahuan di masa mendatang yang lebih baik lagi.

\section{DAFTAR PUSTAKA}

Susanto vita andina. (2018).Asuhan kebidanan nifas dan menyusui.yogyakarta:PT Pustaka baru.

Walyani siwiElisabeth.(2015).asuhankebidanan masa nifas dan menyusui.yogyakarta:PT.Pustaka Baru.

Fatimah. (2019). Pijat perineum.yogyakarta:PT.Pustaka baru.

Mansyur Nurliana. (2014). Asuhan kebidanan masa nifas .malang: selaksa Media.

Maryunani Anik.(2015).Asuhan ibu nifas Dan Asuhan ibu menyusui.Bogor:Penerbit in media.

Maritalia Dewi.(2014).asuhan kebidanan nifas dan menyusui.yogyakarta:pustaka pelajar.

Rukiyah yeyeh Ai.(2018). Asuhan kebidanan pada masa ibu nifas berdasarkan kurikulum berbasis kompetensi.jakarta timur:CV.Trans info Media.

Yanti damai.(2014).Asuhan kebidanan masa nifas:belajar menjadi bidan propesional.bandung:PT.Refika Aditama. 
Asih yusri.(2016).Asuhan kebidanan nifas dan menyusui.jakarta timur:CV.Trans info Media.

Astutik yuli Reni.(2015).Asuhan kebidanan masa nifas dan menyusui .jakarta timur:CV.Trans info media.

Ariani AP.2014.Aplikasi Metodologi penelitian kebidanan dan kesehatan reproduksi.Medika book : Yogyakarta

Rohmin anur.2017.resiko yang mempengaruhi lama penyembuhan luka perineum pada ibu post partum,volume VIII $\quad$ nomor $\quad 3$,hal $449-454$ :jurnal kesehatan(online).https://ejurnal.poltekkestjk.ac.id/index.php/JK/article/view/660/591.

Aditiya nova rizki,2013,Hubungan pengetahuan ibu nifas tentang gizi dengan proses penyembuhan luka perineum.vol $\quad 3 \quad$ no $\quad$ 2:dinamika $\quad$ kebidanan (online).jurnal.abdihusada.ac.id/index.php/jurabdi/article/viewFile/40/40.

Lestari prasetya.(2019).mengurangi ruptur perineum pada ibu hamil.yogjakarta:PT Pustaka baru.

Astriana willy.(2017).mobilisasi di tinjau dari penyembuhan luka perineum.volume 2 no 2 jurnal kesehatan(online).https://jurnal.willyastriana@gmail.com 